\title{
Cancer-Related Pain Management and the Optimal Use of Opioids
}

\author{
O Tratamento da Dor Oncológica e a Utilização Idónea de Opióides
}

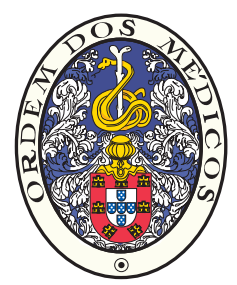

Paulo REIS-PINA $\rrbracket^{1}$, Peter G. LAWLOR ${ }^{2,3,4,5}$, António BARBOSA ${ }^{6,7}$

Acta Med Port 2015 May-Jun;28(3):376-381

\section{ABSTRACT}

Pain relief is vital to the treatment of cancer. Despite the widespread use and recognition of clinical recommendations for the management of cancer-related pain, avoidable suffering is still prevalent in patients with malignant disease. A gap exists between what is known about pain medical management and actual practices of patients, caregivers, healthcare professionals and institutions. Opioids are the pillar of the medical management of moderate to severe pain. The prescription of opioid analgesics - by a registered medical practitioner for absolute pain control - is a legitimate practice. In this article we look at patients' fears and physicians' general hesitations towards morphine and alike. We examine misconceptions that yield fallacies on the therapeutically use of opioids and, therefore, sustain inadequate pain management.

Keywords: Analgesics, Opioid; Neoplasms/complications; Pain/drug therapy; Pain Measurement; Palliative Care.

\section{RESUMO}

O controlo da dor é fundamental no tratamento do cancro. Apesar da vasta utilização e do reconhecimento das normas de orientação clínica para o controlo da dor oncológica, o sofrimento evitável é ainda prevalente em doentes com cancro. Existe um hiato entre o conhecimento e a prática clínica no que concerne a uma adequada gestão da dor pelos doentes, cuidadores, profissionais e instituições de saúde. Os opióides representam o pilar do tratamento farmacológico da dor moderada a insuportável. A prescrição de analgésicos opióides - por um médico credenciado, para o controlo absoluto da dor, - é uma prática legítima. Neste artigo debruçamo-nos sobre as hesitações dos médicos e os receios dos doentes perante a morfina e similares. Examinamos os preconceitos que promovem o fracasso do uso terapêutico dos opióides e, consequentemente condicionam o controlo inadequado da dor.

Palavras-chave: Analgésicos Opióides; Cuidados Paliativos; Dor/tratamento; Medição da Dor; Neoplasias/complicações.

\section{INTRODUCTION}

Pain is one of the most afflicting symptoms reported by cancer patients, mainly those with metastatic disease. ${ }^{1}$ Pain prevalence in advanced cancer is about $70 \%$, but rates vary per both cancer type and disease stage. ${ }^{2}$ Over $80 \%$ of metastatic cancer patients suffer pain caused mostly by direct tumor infiltration. ${ }^{1}$ Surgery, radiotherapy and/ or chemotherapy contribute to, approximately, $20 \%$ of the cases of cancer-related pain (CRP). ${ }^{3}$

\section{PREVALENCE OF CANCER-RELATED PAIN}

Accurate prevalence estimates of pain in cancer patients are not available despite the abundant literature on this topic. Van den Beuken-van Everdingen et al investigated the prevalence of CRP throughout a systematic review of the literature. ${ }^{4}$ Fifty-two studies were used in the metaanalysis. Pooled prevalence rates of pain were calculated for 4 subgroups: patients after curative treatment (33\%); patients under anticancer treatment $(59 \%)$; patients with advanced, metastatic, terminal disease (64\%) and; patients at all disease stages (53\%). More than one-third of the patients had moderate to severe cancer pain (MSCP). Pooled prevalence was above $50 \%$ in all cancer types with the highest prevalence in head/neck cancer patients $(70 \%){ }^{4}$

The European Pain in Cancer (EPIC) was a two-phase telephone survey, held in 11 European countries and Israel, with 5084 adults with all stages of cancer. ${ }^{5}$ From these, $56 \%$ mentioned MSCP, at least, monthly. In a second phase, 573 patients were randomly selected: $90 \%$ had MSCP, $44 \%$ had severe CRP. Global prevalence was $73 \% .^{5}$

\section{UNDERTREATMENT OF CANCER-RELATED PAIN}

Pain considerably weakens quality of life and represents, clinically, an indicator of tumor progression. CRP may be acute or chronic and should be addressed accordingly. ${ }^{3}$

The World Health Organization (WHO) has published some guidelines on CRP management and has been underlining the existence of several treatments, which are effective in $70-90 \%$ of the circumstances. ${ }^{6,7}$

Despite the availability of multiple treatments,

\footnotetext{
1. Palliative Care Unit. Casa de Saúde da Idanha. Sintra. Portugal.

2. Bruyère Research Institute. Bruyère Continuing Care. Ottawa. Ontario. Canada.

3. Division of Palliative Care. Department of Medicine, Epidemiology and Community Medicine. University of Ottawa. Ottawa. Ontario. Canada.

4. The Ottawa Hospital Research Institute. Ottawa. Ontario. Canada.

5. Faculdade de Medicina. Universidade de Lisboa. Lisbon. Portugal.

6. Department of Psychiatry. Hospital de Santa Maria. Centro Hospitalar Lisboa Central, EPE. Lisbon. Portugal.

7. Bioethics and Palliative Care Centre. Faculdade de Medicina. Universidade de Lisboa. Lisbon. Portugal.

$\bowtie$ Autor correspondente: Paulo Reis-Pina. preispina@hotmail.com

Recebido: 06 de Setembro de 2014 - Aceite: 26 de Janeiro de 2015 | Copyright @ Ordem dos Médicos 2015
} 
inadequate management of pain has been found in cancer patients, mainly: seniors, ${ }^{8}$ metastatic outpatients, ${ }^{9}$ children ${ }^{10}$ and minority patients. ${ }^{11}$ This is due to hurdles associated with such factors as: health care providers (HCP), patients, families, institutions, governments and society. ${ }^{12}$ The most frequent cause of undertreatment is misconception about opioids. ${ }^{13}$

Potential causes of undertreatment of CRP are: fear of prescribing opioids, lack of knowledge concerning adequate pain treatment, and patient-related barriers on using opioids. ${ }^{14,15}$ Lack of compliance may cause pain undertreatment, especially if opioids are only prescribed 'as required'. 16

Treatment failure may also be caused by the incapacity to recognize specific cancer pain syndromes. ${ }^{14}$ The Task Force on Cancer Pain of the International Association for the Study of Pain (IASP) identified 22 prevalent pain syndromes and observed that $40 \%$ of cases had a neuropathic component explaining their pain. ${ }^{17}$ Management of that kind of pain involves adjuvant therapies besides classical analgesics. ${ }^{18}$

Large proportions of up to $40 \%$ cancer patients remain intentionally undertreated. ${ }^{19}$

The inadequacy of CRP treatment was also demonstrated by the IASP. ${ }^{17}$ It showed that among 1095 patients treated by pain specialists, $20 \%$ confessed average pain intensity of $\geq 7$ (range 0 - 10) and $67 \%$ reported worse pain of $\geq 7$.

Cleeland et al observed that $42 \%$ of 1308 metastatic cancer outpatients were not given adequate analgesics. ${ }^{9}$

In France, Vainio found that only $25 \%$ of general practitioners (GP) and $44 \%$ of specialists suggested strong opioid to control CRP. ${ }^{20}$ For instance, for metastatic bone pain a third of GP recommended a combination of paracetamol and codeine. Overall, only $10 \%$ of GP and $21 \%$ of specialists prescribed adequate treatment. Consequently, $92 \%$ of the physicians had trouble in managing CRP, inefficacy of treatment being the most important problem. ${ }^{20}$

Sorge et al, in the region of Hannover (Germany), documented that approximately $23 \%$ of GP and $34 \%$ of internal medicine specialists prescribed opioids. In twothirds of cases CRP was the reason for the prescribing. Taking into account the estimated number of cancer patients, less than $20 \%$ of those in need of strong opioids were supplied sufficiently. ${ }^{21}$

A Norwegian survey observed that, even in cancer patients reporting an average pain score of $\geq 7$, only $13 \%$ was prescribed morphine. ${ }^{22}$

In the Treviso district (Italy) a retrospective survey of the opioids prescriptions issued for 2125 cancer outpatients was carried out over the 1993 - 2000 period. ${ }^{23}$ They verified whether patients received adequate opioid prescription accordingly to the Defined Daily Doses (DDD) of opioids suggested by the WHO for a standard population. From the comparison between the number of 'expected opioid DDD' (days for which patients should have been prescribed opioids at the WHO recommended DDD) and the number of 'prescribed opioid DDD' (days for which patients had been offered adequate opioid treatment) for individual patients, it was estimated that only $38 \%$ of prescriptions were adequate. A mean of 55.8 DDD of opioids per patient was not prescribed. The opioid prescription inadequacy increased over time since the first recommendation until the patient's death. ${ }^{23}$

Chinellato et al, in Italy, revealed that only $21 \%$ of dying cancer patients ( $n=39597$ ) were prescribed opioids at the time of death. Prescribed 'morphine equivalent daily dose' was low: morphine (45 mg) and buprenorphine $(53.25 \mathrm{mg})$. Higher doses existed as per injected morphine $(90 \mathrm{mg})$ and per transdermal fentanyl $(180 \mathrm{mg}) \cdot{ }^{24}$

\section{LACK OF OPIOIDS, FEAR OF ADDICTION AND STRICT REGULATION}

Adequate treatment of CRP depends on the availability of safe and effective drugs, capable of relieving chronic MSCP, such as morphine and other opioids. ${ }^{25}$ A successful implementation has been curtailed by the following: lack of opioid analgesics, exaggerated fear of addiction and excessively strict regulation of narcotic drugs. ${ }^{26}$

Across the world, pain patients are facing poor drug availability. About 5.5 billions are living in countries with insufficient or no access to medications for MSCP, according to the WHO's Access to Controlled Medications Programme. ${ }^{27}$

In many countries, the law establishes quantity and duration limits regarding the opioids' prescriptions. Physicians who prescribe them are imposed to fulfill certain requirements. Moreover, HCP and legislators may not realize that there is a need for pain relief; they are likely to be mainly concerned about narcotic addiction and diversion. ${ }^{25}$

Morphine-phobia can be defined as an array of false beliefs based on the negative effects of morphine in the management of pain. It represents an inappropriate attitude of professionals due to lack of knowledge, philosophical opposition to its prescription and morphine administration in pain patients' related myths. ${ }^{28}$ Opioid-phobia seems to be widespread and caused by ignorance, prejudices, false beliefs, economic marketing strategies and limitations in the availability of opioids. ${ }^{29-32}$

In 1986, the WHO recommended that HCP should use a three-step analgesic ladder to treat CRP. ${ }^{6}$ The International Narcotics Control Board transnational survey, performed ten years later, showed that injectable forms of morphine were more available than the oral ones recommended by the $\mathrm{WHO} .{ }^{33}$ In this inquiry, half of the governments reported that morphine was not available in all hospitals where CRP is dealt with. In addition, only $60 \%$ of governments had endorsed WHO's analgesic ladder. ${ }^{33}$

The WHO considers a country's morphine consumption (MOC) to be an important indicator of progress in cancer pain relief ${ }^{34}$ because morphine is the most common opioid analgesic for MSCP. ${ }^{25} \mathrm{MOC}$ for medical purposes was low and stable worldwide for many years until, in 1984, the WHO's cancer pain relief program began. From 1984 to 1991 , global MOC increased by $272 \%,{ }^{35}$ still it remains 
extremely low, and many governments around the world still have to address this chief health priority. ${ }^{25}$

The classic tight regulation of opioids prescription, the ordinance of their use for the treatment of 'narcotic addiction' and the misunderstanding of addiction itself have contributed, altogether, to an even greater confusion regarding licitness of prescription under certain circumstances. ${ }^{36,37}$

Neither physical dependence nor tolerance are sufficient to define addiction. ${ }^{7,38,39}$ In fact, in 1969, the WHO substituted the term 'addiction' for 'drug dependence' which, like addiction, is characterized, primarily, by a compulsive use of a drug despite its harmful effects. ${ }^{40}$ Confusion between physical dependence or tolerance and addiction raises the possibility that an opioid, prescribed to a patient with chronic MSCP, could be viewed as questionable medical practice, if not illegal. ${ }^{39}$ Furthermore, a recent review of literature reports that addiction to opioids is present only in $0-7.7 \%$ of cancer patients, depending on the subpopulation studied and the evaluation criteria used. ${ }^{41}$

On the $12^{\text {th }}$ November 2003 , at the $860^{\text {th }}$ meeting of the Ministers' Deputies, the Committee of Ministers of the Council of Europe, as part of its Recommendation 24 to Member States, declared: "legislation should make opioids and other medicines accessible in a range of formulations and dosages for medical use. The fear of abuse should not hinder access to necessary and effective medication. Countries may wish to consider whether this will require a new legislation whether an amendment should be applied to the existing legislation". ${ }^{42}$

Several criteria are used to evaluate positive or negative medical board policies to pain management. The former identifies policy language that has the potential to enhance pain management and the latter, on the contrary, may impair pain management.

Some positive criteria favouring adequate pain relief are $^{43}$ :

a) Pain management is recognized as part of general medical practice;

b) Controlled substances are recognized as necessary for the public health;

c) Medical use of opioids is recognized as legitimate professional practice;

d) Practitioners' concerns about regulatory scrutiny are addressed;

e) Physical dependence or analgesic tolerance are not mistaken for 'addiction'.

In contrast, negative criteria that impede pain control are ${ }^{43}$ :

a) Opioids are considered a last resort treatment;

b) The belief that opioids hasten death is perpetuated;

c) Medical decisions are restricted: i) based on patient characteristics, ii) mandated consultations, iii) regarding quantity prescribed or dispensed;

d) Length of prescription validity is restricted;

e) Practitioners are under additional prescription requirements.

\section{PHYSICIANS' CONCERNS ON PAIN AND OPIOIDS}

Currently the association 'opioids, pain, and fear' continues to haunt some doctors who assist, on a daily basis, cancer patients and their multidimensional problems. ${ }^{44}$ Things should be different nowadays. Twenty years ago, $18 \%$ of oncologists rated opioids analgesics excessive regulation as one of the top barriers for inadequate CRP management. ${ }^{45}$ Multiple copy prescription schemes and specific formularies for opioids did not ease physicians' hesitations. ${ }^{46}$

Amongst barriers that contribute to inadequate pain treatment, physicians' various fears are not negligenciable. There is fear both of prescribing opioids and of being investigated for prescribing those ${ }^{36}$. Some studies approach that matter.

In the USA, 243 physicians engaged in cancer care misunderstood concepts of morphine tolerance (51\%) and side effects (39\%). Some were unaware of the use of adjuvant analgesics (29\%), efficacy of oral morphine $(27 \%)$ and non-existent risk of addiction (20\%). About $20 \%$ believed that pain was inevitable and could not be diminished by treatment. ${ }^{47}$

Randomly selected licensed American physicians ( $\mathrm{n}=$ 600 ) were surveyed. ${ }^{48}$ The majority considered addiction to be a combination of physiological and behavioral characteristics, rather than defining it solely as a behavioral syndrome. Most physicians felt it lawful and acceptable medical practice to prescribe opioids for CRP, but only half held this view in chronic non-cancer pain. Fewer physicians considered such prescribing if the patient had a history of substance abuse. About two-thirds of physicians were not concerned about being investigated for their opioid prescribing practices, but some admitted that fear and tended to lower the dose prescribed, limit the number of refills, or prescribe WHO's step 1 ou 2 rather than step 3 analgesics. ${ }^{48}$

In France, $76 \%$ of 600 GP and $50 \%$ of 300 oncologists were reluctant to prescribe morphine. ${ }^{49}$ Both groups mentioned fear of side effects as the main reason, as well as concerns about the risk of tolerance, morphine's poor public image and the constraints of prescription forms. Doctors with more prejudice about opioids were women and older oncologists. ${ }^{49}$ Varela \& Aubry revealed, also in France, that more than $60 \%$ of doctors thought that morphine had a ceiling dose. ${ }^{50}$

As per 1082 dying patients, French GP and oncologists prescribe opioids in $85.4 \%$ of them. Prescription was less frequent in the cases of female patients and male physicians, and more frequent if physicians were trained in palliative care. ${ }^{51}$

Ben Diane et al conducted a phone survey amongst a sample of 917 French GP, neurologists and oncologists. Beliefs towards morphine, uneasiness with dying patients, age and female gender were independently associated with reluctance to prescribe morphine. ${ }^{52}$

In northern Italy, 104 GP responded to a questionnaire about opioids. ${ }^{23}$ Most of them feared side effects, such 
as respiratory depression (50\%), constipation (42\%), and addiction (9\%). Many considered opioids capable of reducing length of life (22\%) and inappropriate to pediatric patients (51\%). Some GP experienced pressure by patients' relatives against opioids (44\%) and 58\% considered legislation ineffective for improving their prescribing pattern. ${ }^{23}$

In Canada, Gallagher et al surveyed 4618 physicians on CRP and verified that oncologists had the highest knowledge and surgeons the lowest. Those who practiced in smaller communities had higher knowledge. The questions most frequently answered incorrectly were on equianalgesic $(68 \%)$ and adequate breakthrough dosing (45\%). ${ }^{53}$

In Korea, a nationwide questionnaire survey showed that although physicians had better knowledge of pain management than nurses, both groups lacked knowledge on opioids. Physicians identified perceived patients' reluctance to take opioids as a barrier to pain control. ${ }^{54}$

\section{PATIENTS' ISSUES AND CANCER-RELATED PAIN}

This is a very sensitive matter. On one hand, it is known, patients and their carers or family can act as barriers to pain management and contribute to CRP undertreatment. On the other hand, there are patients complaining about the little assistance their HCP offered in CRP management.

In the EPIC survey, ${ }^{5}$ patients affirmed that CRP: prevented them from concentrating or thinking $(51 \%)$, undermined daily life activities' performance (69\%), made them feel as an increasing burden to others (43\%) and made them unable to self-caring or impede them to help others because they were in too much pain (30\%). Of those still working, $52 \%$ said that pain affected their professional performance. CRP was described as distressing by $67 \%$ of patients, as an intolerable aspect of their cancer by $36 \%$ and $32 \%$ stated that they felt so bad they wanted to die. ${ }^{5}$

Patient beliefs about their HCP were not always fantastic as per EPIC's results. ${ }^{5}$ Patients affirmed that their HCP did not: take into consideration quality of life $(50 \%)$; have enough time to discuss pain (33\%); always ask about pain $(27 \%)$; know how to control pain $(26 \%)$; understand that pain was a problem $(13 \%)$. Their HCP preferred to treat cancer rather than pain $(38 \%) .^{5}$

Most of the articles in the literature depicted patientrelated barriers toward the use of opioids. ${ }^{14,15,55-58}$

In Turkey, 170 patients with CRP were studied, using a questionnaire. ${ }^{57}$ It was found that patients had barriers, mostly in relation to addiction, and to a small extent, physical side effects. It was ascertained that patients having beliefs that acted as barriers to optimal pain management were: male; unmarried; suffering from another chronic disease; self-assessing their average pain intensity as more than 5 in the last 24 hours; using an inadequate analgesic regimen. ${ }^{57}$

Weiss et al - aware that the number of patients experiencing pain remained too high and that putatively most were willing to tolerate pain, - interviewed 988 dying patients from 6 randomly selected USA sites. ${ }^{15}$ Patients were treated by a GP, a pain specialist, or both. Findings showed that $50 \%$ of individuals reported MSCP; $52 \%$ had been assisted by a GP and $20 \%$ consulted a specialist. Of those who had been treated by their GP, $29 \%$ wanted more therapy, $62 \%$ wanted a strategy to remain the same, and $9 \%$ wanted to reduce or stop their pain regimen. Additional therapy was not accepted owing to: fear of addiction, dislike of mental or physical side effects, and not wanting to take more pills or injections. There were no associations between disease and intensity of pain or between disease and the desire for more treatment. Black patients were more likely to seek additional pain therapy, see a specialist, and refuse additional medication because of fear of addiction. ${ }^{15}$

Edrington et al studied the barriers to CRP management in a community sample of 50 Chinese American patients. ${ }^{58}$ Stronger individual barriers found were: tolerance to pain medicine; time intervals used for dosage of pain analgesics; disease progression; and addiction. Significant correlations were found between the tolerance subscale and least pain and the religious fatalism subscale and average pain. These two subscales were positively correlated with anxiety and depression levels. The tolerance subscale was associated with pain interference. Patients' education level, acculturation score, level of depression, and adequacy of pain treatment explained approximately $21 \%$ of the variance in the barriers. ${ }^{58}$

In Korea, nurses pinpointed perceived patients' tendency to under-report of pain as an obstacle to adequate pain control. ${ }^{54}$

A qualitative in-depth interview study was conducted with 18 cancer patients (aged 42 - 88 years). Participants rejected morphine as a medical intervention to control pain and promote quality of life because they saw it only as a comfort measure for the dying. However, opioids were more acceptable if HCP had confidence in opioids and side effects were well managed. ${ }^{59}$

Contrarily to the results above described, in an Australian study some patients mentioned a wish for greater involvement in pain control decisions, perceiving morphine as a facilitator rather than a barrier to good cancer care. In Melbourne, semi-structured interviews were held with 15 cancer patients (aged 24 - 81) presenting to a metropolitan clinic. All of them were highly supportive of morphine use in CRP. For them morphine is useful to treat pain, to enable peace and as a treatment for cancer. ${ }^{60}$

\section{CONCLUSIONS}

Results from retrospective and prospective surveys consistently show that pain is still prevalent in cancer patients. Treatment of CRP is still suboptimal. ${ }^{5,61,62}$

Medical science has learned a great deal about pain management in the last 25 years, even though not all of this knowledge has been incorporated into practice. There is a breach between knowledge and practice as far as adequate pain management is concerned. ${ }^{63}$ Irrational myths exist and affect both patients, caregivers, families, HCP and healthoriented organizations. ${ }^{64,65}$

The increasing number of cancer survivors who live to 
an advanced age proves that it is of paramount importance to reduce the prevalence of pain at all stages of the disease course. ${ }^{4}$ Pain relief should be considered vital to the treatment of cancer. ${ }^{5}$ Incomplete or inaccurate knowledge, and varying attitudes about pain and the use of opioid medications, can and will inhibit pain management. ${ }^{65,66}$

Although there are many effective pharmacological and non-pharmacologic pain treatments available, ${ }^{67}$ opioids are essential for management of MSCP. ${ }^{39}$ Opioid analgesics have been regarded as the bastion of surgery and trauma related pain treatment for many years, ${ }^{36}$ national encouragement of their use for CRP did not occur until roughly ten years ago.

Opioids are controlled substances and are subjected to additional prescription requirements. Their deliberately conditional use, however, is not intended to affect their licit medical use. ${ }^{39}$ The prescription of opioid analgesics for pain control by a registered medical practitioner is a legitimate practice and is recognized as such by regulatory and legislative groups.$^{68}$ Prescribing opioids to former or actual drug abusers is as legitimate, providing it targets pain rather than addiction management. ${ }^{39}$

The advent of new information on pain physiology, opioid pharmacology, and revised conceptions of addiction and dependence - particularly on pseudo-addiction, ${ }^{69}$ represents new knowledge that needs to be incorporated into medical education and practice. ${ }^{36,70}$ Strategies to change physician's attitudes and beliefs regarding morphine

\section{REFERENCES}

1. Cherny NI. The management of cancer pain. CA Cancer J Clin. 2000;50:70-116.

2. Hearn J, Higginson IJ. Cancer pain epidemiology: a systematic review. In: Bruera ED, Portenoy RK, editors. Cancer pain: assessment and management. London: Cambridge University Press; 2003. p. 19-37.

3. Jost LM, ESMO Guidelines Task Force. ESMO minimum clinica recommendations for the management of cancer pain. Ann Oncol. 2005; $16:$ :i83-5.

4. van den Beuken-van Everdingen $\mathrm{MH}$, de Rijke JM, Kessels AG Schouten HC, van Kleef M, Patijn J. Prevalence of pain in patients with cancer: a systematic review of the past 40 years. Ann Oncol. 2007;18:1437-49

5. Breivik H, Cherny N, Collett B, de Conno F, Filbet M, Foubert AJ, et al Cancer-related pain: a pan-European survey of prevalence, treatment, and patient attitudes. Ann Oncol. 2009;20:1420-33.

6. World Health Organization. Cancer pain relief. Geneva: WHO; 1986.

7. World Health Organization. Cancer pain relief with a guide to opioid availability. $2^{\text {nd }}$ edition. Geneva: WHO; 1996.

8. Bernabei R, Gambassi G, Lapane K, Landi F, Gatsonis C, Dunlop R, et al. Management of pain in elderly patients with cancer. SAGE Study Group. Systematic Assessment of Geriatric Drug Use via Epidemiology. JAMA. 1998;279:1877-82.

9. Cleeland CS, Gonin R, Hatfield AK, Hatfield AK, Edmonson JH, Blum $\mathrm{RH}$, et al. Pain and its treatment in outpatients with metastatic cancer. N Engl J Med. 1994;330:592-6.

10. Wolfe J, Grier HE, Klar N, Levin SB, Ellenbogen JM, Salem-Schatz S, et al. Symptoms and suffering at the end of life in children with cancer. N Engl J Med. 2000;342:326-33.

11. Cleeland CS, Gonin R, Baez L, Loehrer P, Pandya KJ. Pain and treatment of pain in minority patients with cancer. The Eastern Cooperative Oncology Group Minority Outpatient Pain Study. Ann Intern Med. 1997;127:813-6.

12. Ripamonti $\mathrm{C}$, De Conno F, Blumhuber $\mathrm{H}$, Ventafridda V. Morphine for relief of cancer pain. Lancet. 1996;347:1262-3.

13. Zenz M, Willweber-Strumpf A. Opiophobia and cancer pain in Europe. in CRP management should focus on tolerance concepts, dosing schemes, safety, efficacy, lack of addictive risk and use of drug combinations. ${ }^{47}$ Of paramount importance, afar from individual misconceptions, is the scientific certainty: CRP can be relieved.

\section{ACKNOWLEDGEMENTS}

We acknowledge the Calouste Gulbenkian Foundation for funding a visiting academic appointment for Peter Lawlor with the University of Lisbon.

\section{PROTECTION OF HUMANS AND ANIMALS}

The authors declare that the procedures followed the regulations established by the Clinical Research and Ethics Committee and to the Helsinki Declaration of the World Medical Association.

\section{DATA CONFIDENTIALITY}

The authors declare having followed the protocols in use at their working center regarding patient's data publication.

\section{CONFLICTS OF INTEREST}

The authors report no conflicts of interest.

\section{FUNDING SOURCES}

This study received no funding from any public, commercial, or not-for-profit sectors.

Lancet. 1993;341:1075-6

14. Klepstad P, Kaasa S, Cherny N, Hanks G, de Conno F, Research Steering Committee of the EAPC. Pain and pain treatments in European palliative care units. A cross sectional survey from the European Association for Palliative Care Research Network. Palliat Med. 2005;19:477-84.

15. Weiss SC, Emanuel LL, Fairclough DL, Emanuel EJ. Understanding the experience of pain in terminally ill patients. Lancet. 2001;357:1311-5.

16. Miaskowski C, Dodd MJ, West C, Paul SM, Tripathy D, Koo P, et al. Lack of adherence with the analgesic regimen: a significant barrier to effective cancer pain management. J Clin Oncol. 2001;19:4275-9.

17. Caraceni A, Portenoy RK. An international survey of cancer pain characteristics and syndromes. IASP Task Force on Cancer Pain. Pain. 1999;82:263-74.

18. Dworkin RH, O'Connor AB, Audette J, Baron R, Gourlay GK, Haanpää $\mathrm{ML}$, et al. Recommendations for the pharmacological management of neuropathic pain: an overview and literature update. Mayo Clin Proc 2010;85:S3-14.

19. Cohen MZ, Easley MK, Ellis C, Hughes B, Ownby K, Rashad BG, et al. Cancer pain management and the JCAHO's pain standards. An institutional challenge. J Pain Symptom Manage. 2003;25:519-27.

20. Vainio A. Treatment of terminal cancer pain in France: a questionnaire study. Pain. 1995;62:155-62.

21. Sorge J, Lüders B, Werry C, Pichlmayr I. Die versorgung von ambulanten tumorpatienten mit opioidanalgetika. Schmerz. 1996;10:283-91.

22. Klepstad P, Loge JH, Borchgrevink PC, Mendoza TR, Cleeland CS, Kaasa $S$. The Norwegian brief pain inventory questionnaire: translation and validation in cancer pain patients. J Pain Symptom Manage. 2001;24:517-25

23. Salvato C, Aretini G, Serraglia D, Terrazzani G, Debetto P, Giusti P, et al. Opioid prescription for terminally ill outpatients in a district of northern Italy: a retrospective survey. Pharmacol Res. 2003;48:75-82.

24. Chinellato A, Terrazzani G, Debetto P, Zambon P, Guzzinati S, Walley T, et al. Retrospective analysis of opioid prescriptions in cancer patients in a northern Italian region. Br J Clin Pharmacol. 2006;62:130-3.

25. Joranson DE, Ryan KM, Jorenby JP. Availability of opioid analgesics 
in Romania, Europe, and the World. Madison: University of Wisconsin Pain \& Policy Studies Group/WHO Collaborating Center for Policy and Communications in Cancer Care; 2003.

26. International Narcotics Control Board. Use of essential narcotic drugs to treat pain is inadequate, especially in developing countries. Press Release 6. Vienna: INCB; 2004.

27. World Health Organization. The access to controlled medications programme. WHO Briefing Note. Geneva: WHO; 2012.

28. Covington EC. Opiophobia, opiophilia, opioagnosia. Pain Med. 2000;1:217-23.

29. Ballantyne JC. Opioids for chronic pain: taking stock. Editorial. Pain. 2006;125:3-4

30. Bandieri E, Chirarolanza A, Luppi M, Magrini N, Marata AM, Ripamonti C. Prescription of opioids in Italy: everything but the morphine. Letter to the editor. Ann Oncol. 2009;20:961-2.

31. Godin G, Bélanger-Gravel A, Eccles M, Grimshaw J. Healthcare professionals' intentions and behaviours: a systematic review of studies based on social cognitive theories. Implement Sci. 2008;3:36.

32. Jacobsen R, Sjoegren P, Moldrup C, Christup L. Physician related barriers to cancer pain management with opioid analgesics: a systematic review. J Opioid Manage. 2007;3:207-14.

33. International Narcotics Control Board. Report of the INCB for 1995: availability of opiates for medical needs. New York: United Nations; 1996.

34. World Health Organization. Cancer pain relief and palliative care: report of a WHO expert committee. Technical report series 804. Geneva: WHO; 1990.

35. Joranson D. Availability of opioids for cancer pain: recent trends, assessment of system barriers, new WHO guidelines, and the risk of diversion. J Pain \& Symptom Manage. 1993;8:353-60.

36. Joranson DE, Gilson AM, Dahl JL, Haddox JD. Pain management, controlled substances, and state medical board policy: a decade of change. J Pain Symptom Manage. 2002:23:138-47.

37. Weissman DE. Doctors, opioids, and the law: the effect of controlled substances regulations on cancer pain management. Semin Oncol. 1993;20:S53-8.

38. Savage SR. Opioid use in the management of chronic pain. Med Clin North Am. 1999;83:761-86.

39. Gilson AM, Joranson DE. Controlled substances and pain management: changes in knowledge and attitudes of state medical regulators. J Pain Symptom Manage. 2001;21:227-37.

40. World Health Organization. Expert Committee on Drug Dependence. 16th report. Technical Report Series 407. Geneva: WHO; 1969

41. Højsted J, Sjøgren P. Addiction to opioids in chronic patients: a literature review. Eur J Pain. 2007;11:490-518.

42. Council of Europe. Rec (2003) 24 of the Committee of Ministers to Member States on the organization of palliative care. [Assessed 2013 Sep 12]. Available at https://wcd.coe.int/ViewDoc.jsp?id=85719.

43. Gilson AM, Joranson DE, Maurer MA. Improving state medical board policies: influence of a model. J Law Med Ethics. 2003;31:119-29.

44. Maltoni M. Opioids, pain, and fear. Editorial. Ann Oncol. 2008;19):5-7.

45. Von Roenn JH, Cleeland CS, Gonin R, Hatfield AK, Pandya KJ. Physician attitudes and practice in cancer pain management: a survey from the Eastern Cooperative Oncology Group. Ann Intern Med. 1993;119:121-6.

46. Wastila LJ, Bishop C. The influence of multiple copy prescription programs on analgesic utilization. J Pharm Care Pain Symptom Control. 1996;4:3-19.

47. Elliott TE, Elliott BA. Physician attitudes and beliefs about use of morphine for cancer pain. J Pain Symptom Manage. 1992;7:141-8.

48. Wolfert MZ, Gilson AM, Dahl JL, Cleary JF. Opioid analgesics for pain control: Wisconsin physicians' knowledge, beliefs, attitudes, and prescribing practices. Pain Med. 2010;11:425-34.

49. Larue F, Colleau SM, Fontaine A, Brasseur L. Oncologists and primary care physicians' attitudes toward pain control and morphine prescribing in France. Cancer. 1995;76:2375-82.

50. Valera JP, Aubry R. Morphine: doctors' beliefs and the myths. Eur J Palliat Care. 2000;7:178-82.

51. Peretti-Watel P, Bendiane MK, Obadia Y, Favre R, Lapiana JM, Moatti JP; et al. The prescription of opioid analgesics to terminal cancer patients: impact of physicians' general attitudes and contextual factors. Palliat Support Care. 2003;1:345-52.

52. Ben Diane MK, Peretti-Watel P, Galinier A, Favre R, Obadia Y; Comité de Pilotage Soins palliatifs PACA. Prescription de morphine en cas de douleur intense en phase terminale de cancer: resultats d'une enquete nationale. Bull Cancer. 2005;92:733-40.

53. Gallagher R, Hawley P, Yeomans W. A survey of cancer pain management knowledge and attitudes of British Columbian physicians. Pain Res Manage. 2004;9:188-94.

54. Jho HJ, Kim Y, Kong KA, Kim DH, Choi JY, Nam EJ, et al. Knowledge, practices, and perceived barriers regarding cancer pain management among physicians and nurses in Korea: a nationwide multicenter survey. PLoS ONE. 2014;9:e105900.

55. Gunnarsdottir S, Serlin RC, Ward S. Patient-related barriers to pain management: the Icelandic Barriers Questionnaire II. J Pain Symptom Manage. 2005;29:273-85.

56. Pargeon KL, Hailey BJ. Barriers to effective cancer pain management: a review of the literature. J Pain Symptom Manage. 1999;18:358-68.

57. Bağçivan G, Tosun N, Kömürcü Ş, Akbayrak N, Özet A. Analysis of patient-related barriers in cancer pain management in Turkish patients. J Pain Symptom Manage. 2009;38:727-37.

58. Edrington J, Sun A, Wong C, Dodd M, Padilla G, Paul S, et al. Barriers to pain management in a community sample of Chinese American patients with cancer. J Pain Symptom Manage. 2009;37:665-75.

59. Reid CM, Gooberman-Hill R, Hanks GW. Opioid analgesics for cancer pain: symptom control for the living or comfort for the dying? A qualitative study to investigate the factors influencing the decision to accept morphine for pain caused by cancer. Ann Oncol. 2008;19:44-8.

60. Grant M, Ugalde A, Vafiadis P, Philip J. Exploring the myths of morphine in cancer: views of the general practice population. Support Care Cancer. 2015; 23:483-9.

61. Azevedo LF, Costa-Pereira A, Mendonça L, Dias CC, Castro-Lopes JM. A population-based study on chronic pain and opioids utilization in Portugal. Pain. 2013;154:2844-52.

62. Portela JL. Prevalence of breakthrough pain in Portugal. Dor 2003;11:23-5.

63. Institute of Medicine. Relieving pain in America: a blueprint for transforming prevention, care, education, and research. Washington: The National Academies Press; 2011.

64. Vieira C, Teixeira A, Juan M, Domingues N, Freitas J, Fragoso M. Pain in hospitalized oncology patients: nurses and physicians records. Eur $\mathrm{J}$ Pain. 2009;13:S224-4a.

65. Pain \& Policy Studies Group. Achieving balance in state pain policy: a progress report card (CY 2012). Madison: University of Wisconsin Carbone Cancer Center; 2013

66. Verloo H, Mpinga EK, Ferreira M, Rapin CH, Chastonay P. Morphinofobia: the situation among the general population and health care professionals in North-Eastern Portugal. BMC Palliative Care. 2010;9:15.

67. Green E, Zwaal C, Beals C, Fitzgerald B, Harle I, Jones J, et al. Cancerrelated pain management: a report of evidence-based recommendations to guide practice. Clin J Pain. 2010;26:449-62.

68. Joranson DE, Gilson AM. Regulatory barriers to pain management. Semin Oncol Nurs. 1998;14:158-63.

69. Weissman DE, Haddox JD. Opioid pseudo-addiction: an iatrogenic syndrome. Pain. 1989;36:363-6.

70. Institute of Medicine. Approaching death: improving care at the end of life. Washington: National Academy Press; 1997. 
Paulo REIS-PINA, Peter G. LAWLOR, António BARBOSA

\section{Cancer-Related Pain Management and the Optimal Use of Opioids}

Acta Med Port 2015:28:376-381

Publicado pela Acta Médica Portuguesa, a Revista Científica da Ordem dos Médicos

Av. Almirante Gago Coutinho, 151

1749-084 Lisboa, Portugal.

Tel: +351218428 215

E-mail: submissao@actamedicaportuguesa.com

www.actamedicaportuguesa.com

ISSN:0870-399X | e-ISSN: 1646-0758

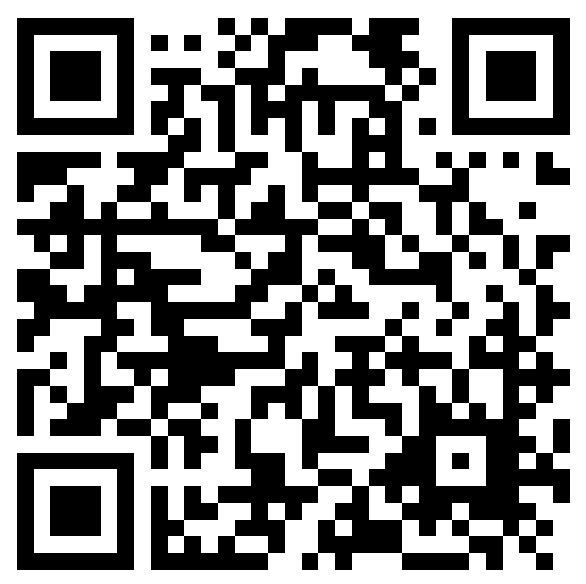

